\title{
STUDI APLIKASI MULTIBEAM ECHOSOUNDER DAN SIDE SCAN SONAR UNTUK MENDETEKSI FREE SPAN PADA SALURAN PIPA BAWAH LAUT
}

\author{
I Made Dwiva Satya Nugraha, Yuwono \\ Jurusan Teknik Geomatika FTSP-ITS, Kampus ITS Sukolilo, Surabaya, 60111 \\ Email : yuwono@geodesy.its.ac.id
}

\begin{abstract}
Abstrak
Saluran pipa bawah laut sebagai salah satu sistem distribusi dalam industri minyak dan gas harus selalu diperhatikan kondisinya agar terhindar dari risiko kerugian material maupun dampak terhadap lingkungan. Salah satu yang harus diperhatikan yakni bentang bebas (free span) atau bagian pipa yang tidak tertumpu. Informasi panjang dan tinggi free span dapat diperoleh melalui survei inspeksi dengan memanfaatkan instrumen hidroakustik, seperti Multibeam Echosounder dan Side Scan Sonar.
\end{abstract}

Ditemukan sebanyak 119 indikasi free span pada citra Side Scan Sonar. Akan tetapi, terdapat selisih posisi horisontal pipa dengan yang terlihat pada data Multibeam Echosounder. Analisis dilakukan terhadap ini dan diketahui bahwa posisi horisontal yang dapat diandalkan adalah posisi pipa dari Multibeam Echosounder. Hal ini disebabkan perambatan kesalahan yang sangat mungkin terjadi pada sistem towing yang diterapkan pada Side Scan Sonar.

Di sisi lain, untuk memperoleh informasi dimensi free span, data yang digunakan adalah citra Side Scan Sonar dikarenakan mampu memberikan informasi kenampakan permukaan dasar laut yang cukup jelas sehingga sangat baik digunakan untuk interpretasi panjang dan tinggi free span..

Kata Kunci: Free Span, Multibeam Echosounder, Pipa Bawah Laut, Side Scan Sonar

\section{PENDAHULUAN}

\section{Latar Belakang}

Energi adalah kebutuhan global yang tidak dapat dipungkiri, terutama minyak dan gas (migas). Permintaan terhadap migas terus meningkat seiring dengan berkembangnya industri migas sehingga harus dibarengi dengan distribusi yang tepat, khususnya pada area lepas pantai. Pembangunan pipa bawah laut merupakan salah satu sistem distribusi pengangkutan material tersebut. Namun, saluran pipa ini memerlukan inspeksi secara berkala untuk menghindari risiko kerugian material terhadap industri itu sendiri dan juga dampaknya terhadap lingkungan, seperti misalnya bila terjadi kerusakan atau kebocoran.

Pipa bawah laut merupakan saluran pipa yang sangat panjang yang digunakan untuk pendistribusian material cair maupun gas antar anjungan atau dari anjungan ke darat. Banyak aspek yang harus diperhatikan dalam perancangan saluran pipa bawah laut, antara lain tebal dinding, pemilihan material, peninjauan rute, pemilihan rute, data lingkungan, perlindungan katodik terhadap korosi, kestabilan pada permukaan dasar laut, analisis tekuk, ekspansi termal, analisis kelelahan, dan analisis terhadap bentang bebas (free span) atau bagian pipa yang tidak tertumpu.

Dinamika di lautan, seperti erosi, sand wave, dan rock beam dapat menyebabkan terjadinya free span. Panjang free span ini sebaiknya dijaga dalam batas yang diizinkan pada proses perancangan baik selama atau setelah instalasi dengan cara memberikan support atau penopang. Untuk mendeteksi free span tersebut dilakukan inspeksi secara berkala. Inspeksi pipa membutuhkan informasi yang teliti mengenai kondisi dasar laut. Survei inspeksi pada umumnya memanfaatkan berbagai macam instrumen hidroakustik, seperti Multibeam Echosounder (MBES) dan Side Scan Sonar (SSS). Alat ini samasama memanfaatkan gelombang akustik, namun memiliki prinsip kerja yang berbeda.

MBES dimanfaatkan untuk survei batimetri, yaitu survei yang dimaksudkan untuk mendapatkan data kedalaman dan topografi dasar laut, termasuk lokasi dan luasan obyek-obyek yang mungkin membahayakan (Subroto, 2012). 
Sedangkan, SSS mampu membedakan besar kecil partikel penyusun permukaan dasar laut, seperti batuan, lumpur, pasir, kerikil, atau tipe-tipe dasar perairan lainnya (Gustiawan, 2012).

\section{Perumusan Masalah}

Perumusan masalah yang dimunculkan dalam penelitian ini adalah sebagai berikut:

1. Bagaimanakah perbandingan data MBES, SSS, dan SBP dalam mendeteksi indikasi free span.

2. Apakah metode terbaik untuk mendeteksi panjang dan tinggi indikasi free span.

\section{METODOLOGI PENELITIAN}

\section{Lokasi Penelitian}

Lokasi penelitian ini berada di Lapangan X, Laut Jawa (bukan lokasi sebenarnya). Detail lokasi studi kasus tidak akan disebutkan di dalam penelitian ini demi privasi perusahaan penyedia data (maps.google.com).

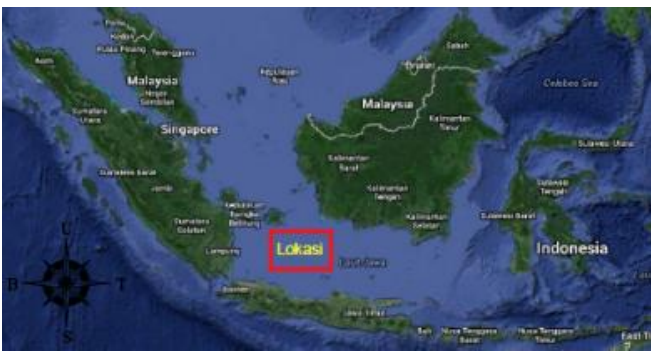

Gambar 1. Lokasi penelitian

\section{Data dan Peralatan}

- Data

Data yang digunakan dalam penelitian ini antara lain:

1. Raw Data Side Scan Sonar.

2. Raw Data Sub-Bottom Profiler.

3. Vektor crossline survei Sub-Bottom Profiler.

4. Data ASCII Multibeam Echosounder.

- Peralatan

Peralatan yang digunakan dalam penelitian ini adalah perangkat keras berupa satu unit computer dan plotter serta perangkat lunak untuk pengolahan data spasial survey hidrografi.

\section{Diagram Alir Pengolahan Data}

Secara garis besar tahapan dari pengolahan data yang dilakukan adalah seperti pada diagram alir berikut.

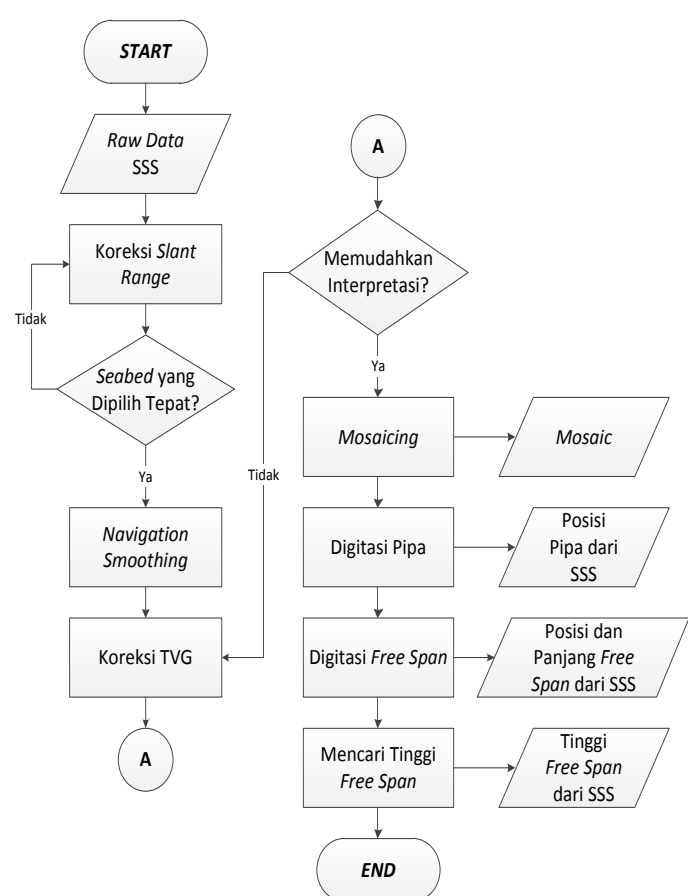

Gambar 2. Diagram Alir Pengolahan Data SSS

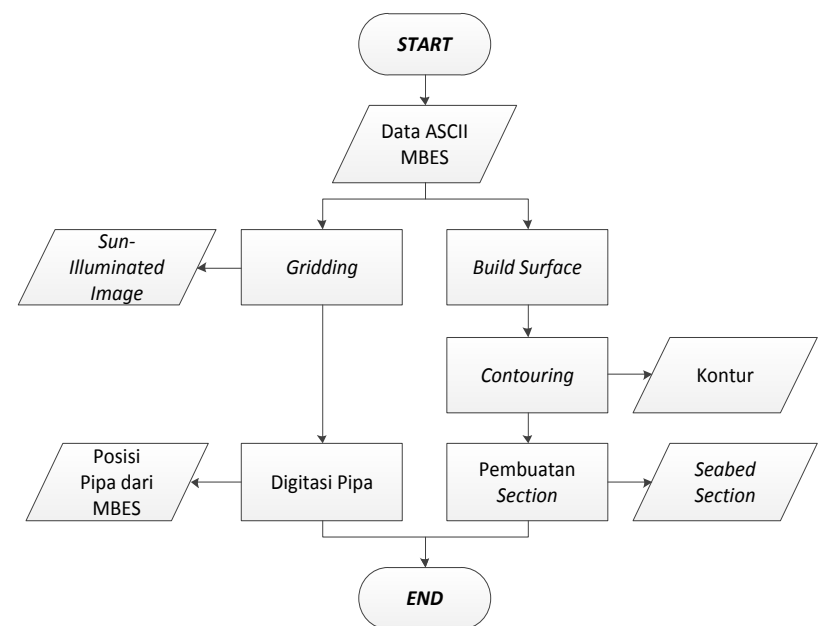

Gambar 3. Diagram Alir Pengolahan Data ASCII MBES

\section{Tahap Pengolahan Data Sonar Image}

Sonar image atau citra gambaran permukaan dasar laut diperoleh dengan bantuan Side Scan Sonar 272 TD Dual Frequency yang menghasilkan citra dengan frekuensi rendah dan tinggi secara bersamaan. Pengolahan data dilakukan dengan menerapkan koreksi jarak miring (slant range) terhadap area putih atau disebut dengan kolom air yang terekam pada sonar image, dilanjutkan 
dengan koreksi navigasi untuk mengurangi jumping koordinat pada rekaman SSS, dan koreksi time-varying gain (TVG) yakni mengatur backscatter yang mempengaruhi rona. Setelah semua citra dikoreksi, maka dibuatlah suatu mosaic dari citra-citra tersebut untuk dapat dilakukan interpretasi pipa dan dimensi free span pipa.

\section{Tahap Pengolahan Data Batimetri}

Data batimetri didapat dari akuisisi dengan menggunakan instrumen akustik Single beam Echosounder Odom Echotrac MKII dan Multibeam Echosounder Simrad EM3002. Sistem pemposisian menggunakan metode diferensial (Lekkerkerk, 2006) dengan DGPS C-Nav 2050 bereferensi pada datum WGS84 pada jalur survei sepanjang \pm 14 kilometer. Koreksi yang diterapkan saat pengolahan data diantaranya pembersihan terhadap gangguan data atau yang biasa disebut spike yang terjadi akibat operasional kapal, gelembung air, dan faktor-faktor lainnya, lalu koreksi profil kecepatan suara, serta pasang surut untuk mereduksi kedalaman yang diperoleh terhadap variasi muka air laut. Namun dikarenakan data MBES yang diperoleh sudah dalam bentuk ASCII, maka tidak dipelukan lagi proses koreksi data. Sehingga pengolahan yang dilakukan dalam penelitian ini adalah untuk mendapatkan sun-illuminated image untuk digitasi pipa dan seabed section sepanjang saluran pipa.

\section{HASIL DAN PEMBAHASAN}

\section{Hasil}

Hasil dari proses pengolahan adalah sebagai berikut:

a. Perbedaan Posisi Pipa dari Data SSS dan MBES Saluran pipa bawah laut terlihat jelas pada Sonar image, begitu pula dengan free span yang ditandakan oleh adanya bayangan atau yang biasa disebut acoustic shadow. Interpretasi dilakukan dengan mendigitasi citra yang dibatasi hanya pada kenampakan saluran pipa dan panjang free span-nya saja. Namun, terdapat kejanggalan pola pipa yang tampak melekuk tidak lazim bila dibandingkan dengan hasil digitasi pipa dari data MBES. Sampel yang ditampilkan pada tabel diambil dari free span citra SSS dan free span citra SSS yang disesuaikan dengan posisi pipa MBES.

Tabel 1. Komparasi Free Span dari Data MBES dan SSS

\begin{tabular}{|c|c|c|c|c|c|c|c|}
\hline \multirow{2}{*}{$\begin{array}{l}n \\
\frac{n}{5}\end{array}$} & \multicolumn{3}{|c|}{ Koordinat Awal Span } & \multicolumn{3}{|c|}{ Koordinat Akhir Span } & \multirow{2}{*}{$\begin{array}{l}\text { Data } \\
\text { Pipa }\end{array}$} \\
\hline & $\begin{array}{l}\text { Easting } \\
\qquad(m)\end{array}$ & $\begin{array}{c}\text { Northing } \\
(m)\end{array}$ & $\begin{array}{l}\text { Jarak } \\
(\mathrm{m})\end{array}$ & Easting $(m)$ & $\begin{array}{l}\text { Northing } \\
\text { (m) }\end{array}$ & $\begin{array}{c}\text { Jarak } \\
(\mathrm{m})\end{array}$ & \\
\hline \multirow{2}{*}{3} & 513590,89 & 9417666,96 & \multirow{2}{*}{6,22} & 513594,95 & 9417665,37 & \multirow{2}{*}{6,90} & MBES \\
\hline & 513587,73 & 9417661,61 & & 513591,49 & 9417659,40 & & SSS \\
\hline \multirow{2}{*}{5} & 513830,10 & 9417578,86 & \multirow{2}{*}{5,82} & 513834,34 & 9417577,44 & \multirow{2}{*}{6,16} & MBES \\
\hline & 513827,77 & 9417573,53 & & 513831,90 & 9417571,79 & & SSS \\
\hline \multirow{2}{*}{6} & 513877,03 & 9417563,31 & \multirow{2}{*}{8,06} & 513881,75 & 9417561,65 & \multirow{2}{*}{8,00} & MBES \\
\hline & 513874,45 & 9417555,68 & & 513879,19 & 9417554,07 & & SSS \\
\hline \multirow{2}{*}{9} & 514192,21 & 9417440,15 & \multirow{2}{*}{5,26} & 514195,86 & 9417438,55 & \multirow{2}{*}{5,45} & MBES \\
\hline & 514189,88 & 9417435,43 & & 514193,45 & 9417433,67 & & SSS \\
\hline \multirow{2}{*}{18} & 515134,59 & 9416907,21 & \multirow{2}{*}{6,46} & 515145,83 & 9416900,64 & \multirow{2}{*}{7,01} & MBES \\
\hline & 515130,94 & 9416901,88 & & 515141,90 & 9416894,84 & & SSS \\
\hline
\end{tabular}

Perbedaan tidak hanya terjadi pada koordinat seperti yang disebutkan pada tabel di atas. Perbedaan yang ditampilkan dipilih hanya yang selisihnya lebih dari 5 meter pada awal atau akhir span-nya. Dapat dilihat bahwa selisih jarak maksimum antara pipa dari data MBES dibandingkan dengan SSS masing-masing sebesar 8,06 meter pada awal span dan 8,00 meter pada akhir span yang terjadi pada free span nomor 6.

\section{b. Free Span yang Terdeteksi}

Saluran pipa dimulai pada koordinat Easting 512882,27 meter dan Northing 9418084,26 meter (bukan koordinat sebenarnya) dengan kedalaman 46,30 meter di bawah chart datum yang ditandai sebagai Kilometer Post (KP) 0,0. Terdapat sebanyak 119 free span pada saluran pipa sepanjang 13,058 kilometer ini dengan panjang dan tinggi terhadap dasar laut yang bervariasi.

Tabel 2. Free Span pada Saluran Pipa 26" di Lapangan

\begin{tabular}{ccccccc}
\multicolumn{7}{c}{$\mathbf{X}$} \\
\hline \multirow{2}{*}{ Span } & \multicolumn{2}{c}{ Koordinat Awal Span } & \multicolumn{2}{c}{ Koordinat Akhir Span } & \multicolumn{2}{c}{ Dimensi } \\
\cline { 2 - 7 } & Easting $(\boldsymbol{m})$ & Northing $(\boldsymbol{m})$ & Easting $(\boldsymbol{m})$ & Northing $(\boldsymbol{m})$ & $\mathbf{P}(\mathbf{m})$ & $\mathbf{T}(\mathbf{m})$ \\
\hline $\mathbf{1}$ & 513123,01 & 9417898,92 & 513136,39 & 9417890,16 & 15,99 & 0,52 \\
$\mathbf{2}$ & 513356,96 & 9417765,54 & 513358,61 & 9417764,74 & 1,83 & 0,33 \\
$\mathbf{4 0}$ & 583057,56 & 9919895,66 & 583058,54 & 9919895,25 & 1,07 & 0,32 \\
$\mathbf{4 1}$ & 518295,89 & 9415268,70 & 518299,60 & 9415266,34 & 4,40 & 0,37 \\
$\mathbf{4 2}$ & 518490,85 & 9415108,46 & 518492,62 & 9415106,61 & 2,57 & 0,31 \\
$\mathbf{8 5}$ & 585807,25 & 9917028,91 & 585808,13 & 9917027,06 & 2,05 & 0,19 \\
$\mathbf{8 6}$ & 520849,80 & 9412450,47 & 520850,63 & 9412449,11 & 1,59 & 0,26 \\
$\mathbf{8 7}$ & 520972,70 & 9412271,11 & 520973,66 & 9412269,96 & 1,50 & 0,32 \\
$\mathbf{1 0 8}$ & 587087,99 & 9916122,80 & 587144,93 & 9916120,51 & 56,98 & 2,03 \\
$\mathbf{1 0 9}$ & 522146,53 & 9411620,47 & 522169,50 & 9411619,86 & 22,98 & 1,45 \\
$\mathbf{1 1 9}$ & 523153,90 & 9411977,82 & 523177,14 & 9411990,39 & 26,43 & 0,27 \\
\hline
\end{tabular}


Keterangan:

$\mathrm{P}$ : panjang free span dalam meter

$\mathrm{T}$ : tinggi free span dalam meter

\section{Pembahasan}

a. Analisis Perbedaan Posisi Pipa dari Data SSS dan MBES

Hasil interpretasi dan digitasi mosaic SSS menghasilkan pola pipa yang tampak tidak wajar dibandingkan dengan digitasi pipa menggunakan sun-illuminated imege mengingat instalasi pipa sangat memperhatikan faktor kelurusan pipa. Perbedaan pola pipa dari kedua metode ditunjukkan oleh gambar berikut.

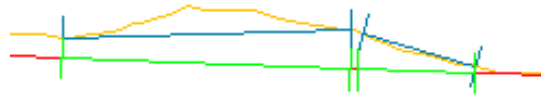

Gambar 4. Free Span 108 dan 109 dari Data MBES dan SSS

Keterangan:

$\square$
$\square \quad$ digitasi pipa dari data MBES
$\quad$ free span dari data SSS
$\quad$ free span disesuaikan dengan digitasi
pipa MBES

Melirik kembali prinsip kerja untuk masalah positioning, kedua alat ini bergantung pada DGPS (Lekkerkerk, 2006). Walaupun menggunakan sistem pemosisian yang sama, data komparasi menunjukkan posisi pipa yang dihasilkan berbeda. SSS mengakuisisi data dengan prinsip towing atau ditarik dengan tow cable, sehingga dapat dikatakan positioning SSS tidak langsung terhubung dengan GPS melainkan melalui perantara suatu sistem tambahan yaitu Ultra Short Baseline (USBL). Hal ini memungkinkan terjadinya perambatan kesalahan, yaitu kesalahan offset transduser USBL terhadap GPS dan kesalahan sistem USBL sendiri terhadap SSS, sehingga berdampak pada kualitas posisi pipa dan free span-nya yang kurang bisa diandalkan. Ditambah lagi stabilitas Sonar Fish yang sangat dipengaruhi arus dan gelombang saat mengakuisisi data (Lekkerkerk, 2006).

Sistem MBES dalam penelitian ini adalah mounted, di mana tidak terdapat sistem lain untuk mengintegrasikan GPS dengan transduser. Yang perlu diperhatikan adalah offset transduser MBES terhadap GPS, sehingga posisi yang diperoleh dapat dianggap benar dan dijadikan sebagai data posisi primer. Namun, free span tidak terlihat pada sunilluminated image MBES, kecuali free span dengan tinggi yang ekstrim, sehingga interpretasi pipa dan free span-nya pun sulit dilakukan karena semua benda yang ditangkap sebagai data pada dasarnya adalah berupa kumpulan titik.

b. Nilai Dimensi Free Span Terendah dan Tertinggi

Posisi free span pada Tabel 2 merupakan posisi free span dari sonar image yang disesuaikan dengan posisi saluran pipa dari data MBES. Sedangkan tinggi free span adalah yang diperoleh dari sonar image. Free span nomor 108 memiliki panjang span 56,98 meter dan tinggi sebesar 2,03 meter di atas permukaan dasar laut. Angka ini merupakan nilai panjang dan tinggi span terbesar dari semua free span saluran pipa 26" di Lapangan X, Laut Jawa (bukan lokasi sebenarnya). Bentang terpendek dimiliki oleh free span 40 dan untuk tinggi terendah pada free span 85. Untuk kenampakan free span yang lebih jelas dapat dilihat di lampiran.

\section{PENUTUP}

Pendeteksian free span dalam penelitian ini menggunakan data Side Scan Sonar dan Multibeam Echosounder. Posisi yang diperoleh dari data Multibeam Echosounder menjadi data posisi pipa yang dapat dianggap benar, melirik pada sistem mounted instrumen ini di kapal survei.

Di lain sisi, citra Side Scan Sonar mampu memperlihatkan kenampakan permukaan dasar laut yang cukup jelas sehingga sangat baik digunakan untuk interpretasi panjang dan tinggi free span. Metode terbaik untuk memperoleh dimensi free span adalah dengan mengkombinasikan kelebihan yang dimiliki instrumen hidroakustik ini. Data posisi menggunakan data Multibeam Echosounder dan 
dimensi free span diperoleh dari interpretasi citra side Scan Sonar.

Diperoleh bahwa free span 108 merupakan yang terpanjang dan tertinggi dengan panjang span $56,98 \mathrm{~m}$ dan tinggi 2,03 $\mathrm{m}$ di atas permukaan dasar laut. Bentang terpendek dimiliki oleh free span 40 dengan panjang $1,07 \mathrm{~m}$ dan untuk tinggi terendah pada free span 85 dengan nilai 0,19 m.

\section{DAFTAR PUSTAKA}

Subroto, R. Y. 2012. Pengolahan Data Multibeam Echosounder Pada Survei Pra-Pemasangan Pipa Bawah laut. Bandung: Program Studi Teknik Geodesi dan Geomatika ITB.

Gustiawan, H. 2012. Komputasi Data Side Scan Sonar Klein 3000 untuk Identifikasi Targat Dasar Laut. Bogor: Departemen IImu dan Teknologi Kelautan IPB.

Lekkerkerk, H.-J., Velden, R. v., Haycock, T., Jansen, P., Vries, R. d., Waalwijk, P. v., et al. 2006. Handbook of Offshore Surveying Volume One: Preparation \& Positioning. London: Clarkson Research Service Limited.

\section{LAMPIRAN}

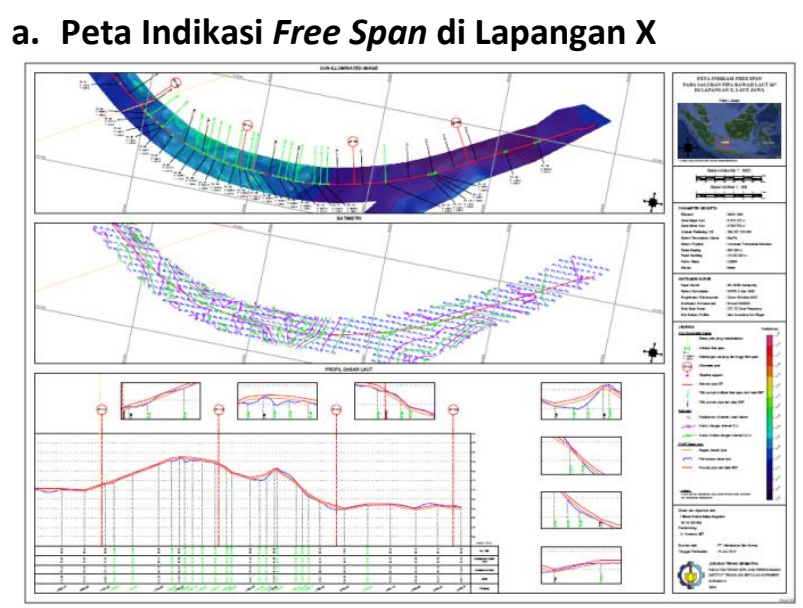

b. Free Span 38, 39, dan 40 pada Citra Side Scan Sonar

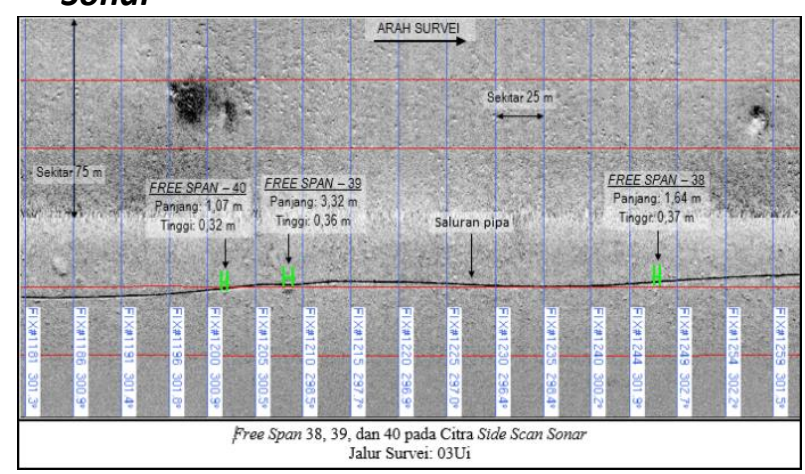

